\title{
Nutrition support in cardiac surgery patients: Be calm and feed on!
}

\author{
Christian Stoppe, MD, ${ }^{\mathrm{a}}$ Richard Whitlock, MD, ${ }^{\mathrm{b}}$ Rakesh C. Arora, MD, PhD, ${ }^{\mathrm{c}}$ and Daren K. Heyland, $\mathrm{MD}^{\mathrm{d}}$
}

\footnotetext{
From the ${ }^{\mathrm{a}}$ Department of Intensive Care Medicine and 3CARE, University Hospital of the RWTH Aachen, Aachen, Germany; ${ }^{\mathrm{b}}$ Department of Surgery, Population Health Research Institute, McMaster University, Hamilton, Ontario, Canada; ${ }^{c}$ Department of Surgery, Max Rady College, University of Manitoba, Winnipeg, Manitoba, Canada; and ${ }^{\mathrm{d}}$ Department of Critical Care Medicine, Queen's University and the Clinical Evaluation Research Unit, Angada 4, Kingston General Hospital, Kingston, Ontario, Canada.

Received for publication Jan 29, 2019; revisions received Feb 27, 2019; accepted for publication Feb 28, 2019; available ahead of print June 13, 2019.

Address for reprints: Christian Stoppe, MD, Department of Intensive Care Medicine and 3CARE, University Hospital of the RWTH Aachen, Pauwelsstraße 30, 52074 Aachen, Germany (E-mail: christian.stoppe@gmail. com).

J Thorac Cardiovasc Surg 2019;158:1103-8

$0022-5223 / \$ 36.00$

Copyright (C) 2019 by The American Association for Thoracic Surgery

https://doi.org/10.1016/j.jtcvs.2019.02.132
}

Advances in surgical procedures, anesthesia, perioperative management, and new technologies have facilitated continued improvements in patients' outcomes and mortality reduction after cardiac surgery. However, this may not be enough for the contemporary patient undergoing cardiac surgery, with even greater comorbidities and frailty. ${ }^{1}$ Indeed, vulnerable older adult patients who experience a complicated or prolonged intensive care unit (ICU) stay after surgery remain impaired for years, with many of them never returning to work and a normal life after the ICU stay. ${ }^{2,3}$ One major factor contributing to this "post-ICU disability" is the loss of functional lean body mass, highlighting the importance of nutrition support as an integral component of the perioperative care of cardiac surgery patients. Since the first description of nutrition therapy in cardiac surgery patients in 1974 by Manners ${ }^{4}$ and Stoppe and colleagues, ${ }^{5}$ it has taken more than 3 decades years until the crucial role of adequate nutrition support has been "rediscovered."

\section{PERIOPERATIVE CARE: CARDIAC SURGERY PATIENTS NEED NUTRITION SUPPORT!}

A patient's preoperative nutritional status represents an important driver for clinical outcomes. Malnutrition, defined as an unintentional nutritional intake imbalance (not necessarily a decreased intake), is evident in $20 \%$ of patients before cardiac surgery. Well-nourished patients have better outcomes and lower postoperative mortality after cardiac surgery, 6,7 indicating the need for effective nutrition strategies to optimize malnourished patients before surgery. In this context, the International Society for Enhanced Recovery After Surgery (ERAS) recently launched a multimodal subspecialty group for optimal perioperative care of cardiac surgery patients, "ERAS Cardiac," with the overall goal to reduce surgical stress, maintain physiologic functional capacity, and facilitate

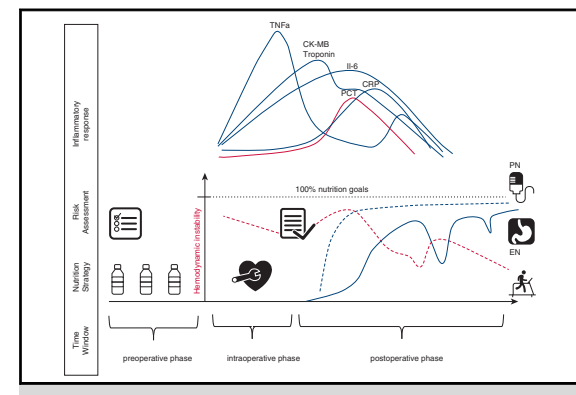

Perioperative nutrition support in high-risk cardiac surgery patients.

Central Message

Although easily doable, proven safe, and clinically relevant, nutrition support still remains largely inadequate in the perioperative treatment of cardiac surgery patients.

The Invited Expert Opinion provides a perspective on this topic based on the following paper: Nutrients. 2018;10:597. https://doi.org/10.3390/ nu10050597.

See Commentaries on pages 1109 and 1111.

postoperative recovery through evidence-based best practice. An integral component of these practice bundles includes preoperative and postoperative nutrition strategies developed to optimize the nutritional status of cardiac surgery patients with nutritional risk. 5,8,9

An inadequate or delayed initiation of nutritional support after surgery may aggravate preexisting malnutrition of cardiac surgery patients. Therefore, there is an urgent need to systematically identify malnourished patients who would most likely benefit from early initiated intense perioperative nutrition support. Until now, no prospectively validated nutrition risk tools are available for cardiac surgical patients. On the basis of existing nutritional assessment tools, most ICU and post-cardiac surgery patients would uniformly be classified to be at high nutritional risk, ${ }^{10}$ irrespective of the patients' operative risk or the length of their ICU stay. Because nutritional deficiencies are known to increase with the ICU length of stay, the prediction of prolonged ICU stay represents an alternative approach for risk stratification. These patients are more likely to benefit and should be identified early to receive intense early nutritional support. ${ }^{11,12}$ Recent data have demonstrated the utility of a 
combined model, including the European System for Cardiac Operative Risk Evaluation, cardiopulmonary bypass, and mini-nutrition assessment risk score for the prediction of prolonged ICU stay in cardiac surgery patients. ${ }^{13}$ If confirmed in prospective validation studies, it would enable an earlier initiation of aggressive postoperative nutrition therapy to prevent a worsening of malnutrition and facilitate an ERAS. ${ }^{13}$

\section{WHAT CAN THE PERIOPERATIVE CARDIAC SURGERY SPECIALIST LEARN FROM RECENT STUDIES? \\ The Right Timing: When to Start Nutrition Support}

Although few large-scale studies are currently focusing on how to attenuate the perioperative inflammatory response by immune-modulating pharmaconutrients (eg, SUSTAIN CSX study ${ }^{14}$ ), little evidence exists about how and when to start enteral nutrition (EN) and parenteral nutritional (PN) support after cardiac surgery. A timely initiation of adequate nutrition support is of special relevance for malnourished cardiac surgery patients and those with prolonged ICU stay after complex or combined surgical procedures. ${ }^{15}$ In this vulnerable population, insufficient nutrition support is associated with an increased rate of infections, poor wound healing, reduced respiratory muscle mass, delayed weaning from mechanical ventilation, increased length of ICU stay, increased readmission rates, high health care costs, and shorter survival time. ${ }^{5,11,16}$ Because of sparse evidence, nutrition support and initiation of EN are often withheld during the early postoperative course of cardiac surgery patients and often considered harmful. The commonly observed low cardiac output syndrome and prolonged need of vasoactive medications after surgery represent common reasons for late initiation and restrictive use of nutrition support in cardiovascular ICU patients. ${ }^{17} \mathrm{~A}$ delay in initiating postoperative nutritional support and an inadequacy of caloric intake and protein intake ( $\sim 70 \%$ less than the recommended intake) have been reported in cardiac surgery patients. ${ }^{16}$ Furthermore, gastrointestinal intolerance and fasting for procedures and interventions often result in less than $60 \%$ of recommended energy delivery compared with general ICU patients. ${ }^{18}$

\section{How to Reach Nutritional Targets}

On the basis of this failure to deliver the required energy targets, the recently published multicenter randomized controlled TARGET trial tested whether delivering a higher number of calories using an energy-dense EN product $(1.5 \mathrm{kcal} / \mathrm{mL})$ would result in higher rates of survival of mechanically ventilated ICU patients within 90 days compared with lower caloric doses delivered using a standard EN feeding product $(1.0 \mathrm{kcal} / \mathrm{mL}) .{ }^{19}$ The resulting data demonstrated that the use of energy-dense nutrition $(23.1 \pm 7.1 / \mathrm{kg}$ actual body weight) significantly increased the energy intake to full recommended goals, whereas patients in the routine EN group received only approximately $60 \%$ $(15.6 \pm 4.8 \mathrm{kcal} / \mathrm{kg}$ actual body weight $)$ of the recommended energy goals. Regarding the primary end point, the rate of survival at 90 days did not differ between the treatment groups. Further, no significant effect was demonstrated with regard to the secondary end points, and the results were similar in the predefined subgroups. ${ }^{19}$ Considering potential limitations, the protein delivery remained $40 \%$ to $50 \%$ below the currently recommended goals and was the same in both groups, although the importance of an adequate protein support is recognized as a key component of nutritional support and recommended at significantly higher doses by recently updated international guidelines. ${ }^{20}$

The results of available studies addressing the relationship between energy delivery and outcomes after critical illness reported conflicting results: On the one hand, few studies demonstrated that nutrition support below the recommended goals (so-called permissive underfeeding $(\sim 1000 \mathrm{kcal} /$ day $)$ or trophic feeding $(\sim 400 \mathrm{kcal} / \mathrm{day})$ is not associated with worse outcomes or adverse events, ${ }^{21,22}$ whereas other studies have demonstrated that increasing delivery improves outcomes. ${ }^{11,23,24}$ The underlying reasons for these differing results may be due to the fact that not all critically ill patients benefit in the same manner from a nutrition support. ${ }^{25}$ Although a nutritional risk assessment is recommended by current international guidelines and needed to identify patients who may respond to intensive nutritional support, no risk assessment or stratification was performed in the TARGET trial and thus all critically ill patients were considered at the same nutritional risk. Previous studies demonstrated that not all ICU patients are the same, and there are some who benefit more or less from artificial protein-energy provision in the critical care setting. ${ }^{16}$ Therefore, it is not surprising that overall, regardless of the nutritional risk, the energy-dense nutritional support did not affect mortality or key secondary outcomes, including organ injury and duration of hospital stay in the analyses of the cohort patients.

\section{The Right Route for Nutrition Support During the Early Phase of Critical Illness}

International nutrition guidelines uniformly recommend that EN feeding shall be initiated within 24 to 48 hours in the critically ill patient who is unable to maintain oral volitional intake, because it promotes gut mucosal proliferation, maintains gut integrity, and enhances immune functions. This may lead to decreases in infectious complications and ICU/hospital length of stay and reduced mortality. ${ }^{26,27}$ Although previous studies reported mild adverse effects (eg, gastrointestinal intolerances) associated with early initiation of EN feeding, ${ }^{28}$ recent data from the TARGET study demonstrated that an early delivery of energy-dense 
EN feeding was feasible, safe, and effective in increasing the energy intake. Nonetheless, it was mainly performed in medical ICU patients and did not affect outcomes. ${ }^{19}$ Likewise, in patients after cardiac surgery, EN feeding alone is often not effective to achieve nutrition targets within 24 to 48 hours after surgery, resulting from hemodynamic instability or gastrointestinal intolerance. ${ }^{29}$ During the initial phase of the acute illness, energy-dense EN products may represent an attractive option to achieve these nutrition goals in cardiac surgery patients with complex procedures and prolonged ICU stay. Compared with all other surgical or medical ICU patients, cardiac surgery is most often associated with iatrogenic malnutrition. ${ }^{30}$ Rahman and colleagues ${ }^{16}$ showed that cardiac surgery patients received only approximately $20 \%$ to $30 \%$ of their energy and protein goals. In view of these alarming findings, the use of energy-dense EN may represent an important and underappreciated strategy to effectively reduce these nutritional deficiencies early in the postoperative course, which needs to be tested.

\section{Combined Enteral + Parenteral Nutrition as a Potential Strategy to Reduce Nutritional Deficiencies}

An extension to energy-dense EN, the use of PN in combination with EN (combined EN + PN) is increasingly considered a promising strategy to reduce the nutritional deficiencies during the early phase of acute illness. Guidelines already suggest that PN should be started in patients in whom EN cannot reach nutritional goals. Several randomized controlled studies have reported the effects of combined $\mathrm{EN}+\mathrm{PN}^{23,31,32}$ and indicate a faster functional recovery in critically ill patients. Although EN is thought to be cheaper, safer, and more physiologic, and is recommended by international nutrition guidelines in critically ill patients without a contraindication to $\mathrm{EN},{ }^{15,33-35}$ recent data have demonstrated that combined $\mathrm{PN}+\mathrm{EN}$ is effective in increasing calorie and protein delivery during the first ICU week and thus may provide an advantage in cardiac surgery patients to rapidly achieve targeted nutritional goals in comparison with EN alone. $^{32}$

Although a previous study indicated that the use of PN may be associated with more infectious complications, ${ }^{36,37}$ caused by high glucose use and hyperalimentation, Harvey and colleagues ${ }^{38}$ demonstrated in the randomized controlled CALORIES trial that mortality and infectious complications were similar in patients receiving total PN or EN alone. These results challenge the dogma that EN is superior to PN with respect to clinical outcomes in critical illness. In the large-scale NUTRIEREA-2 trial, Reignier and colleagues ${ }^{28}$ investigated whether the route of feeding affects the outcomes of critically patients in shock. In this multicenter randomized controlled study, critically ill patients on vasopressor support for shock were randomly assigned to PN or EN alone, both targeting normocaloric goals within 24 hours after intubation. The resulting data demonstrated that the early isocaloric EN reduced neither the mortality nor the risk of secondary infections; however, it was associated with greater digestive complications when compared with patients receiving early isocaloric PN. Among critically ill patients, nutritional deficiencies were most significant in patients after cardiac surgery. Nutritional support is often withheld because of concerns for paralytic ileus, ischemia/reperfusion injury related to prolonged clamping of the aorta, and prolonged vasopressor support or hemodynamic instability. ${ }^{8}$ In this context, the concept of combining EN + PN may represent a promising strategy to increase the nutrition delivery in these critically ill patients. Preliminary evidence indicates beneficial effects of combined $\mathrm{PN}$ and $\mathrm{EN}(\mathrm{PN}+\mathrm{EN})$ in a general ICU population. These data demonstrated that the combined EN + PN strategy was effective to increase the nutrition delivery, ${ }^{23,32}$ whereas such strategies have not been tested in cardiac surgery patients. Figure 1 illustrates an optimal perioperative nutrition support may be achieved by combining $\mathrm{EN}+\mathrm{PN}$ in cardiac surgery patients at nutritional risk (Figure 1).

\section{BEYOND NUTRITIONAL SUPPORT}

Although overall mortality rates are low, increasing attention needs to be made on how to minimize morbidity in vulnerable cardiac surgery patients to ensure enhanced recovery after their procedure. These observations point out the importance of developing new strategies of combined nutrition and ICU-based rehabilitation to promote the physical recovery of these patients. ${ }^{39,40}$ Specifically, we must seek to develop strategies to identify risks, provide opportunities for preoperative optimization to prevent the loss of lean body mass, and accelerate functional recovery, especially in patients at risk of a prolonged ICU stay. In particular, patients with complex and combined surgical procedures are at increased risk for prolonged organ-supporting therapies and commonly develop neuromuscular abnormalities. ${ }^{39,40}$

Conceptually, increasing evidence indicates that besides nutrition alone, combined preoperative and ICU-based exercise/rehabilitation interventions may further increase the clinical benefits of nutritional support. ${ }^{41}$ In conjunction with enhanced use of nutrients, this approach may help to prevent or attenuate ICU-acquired deconditioning, potentially mitigate delayed weaning from mechanical ventilation, and reduce extended ICU and hospital stays. Overall, this combined approach has the potential to reduce mortality rates, healthcare-related costs, and enhance early recovery after ICU admission. ${ }^{39,40,42}$ An international, multicenter, randomized controlled study (Support CSX 


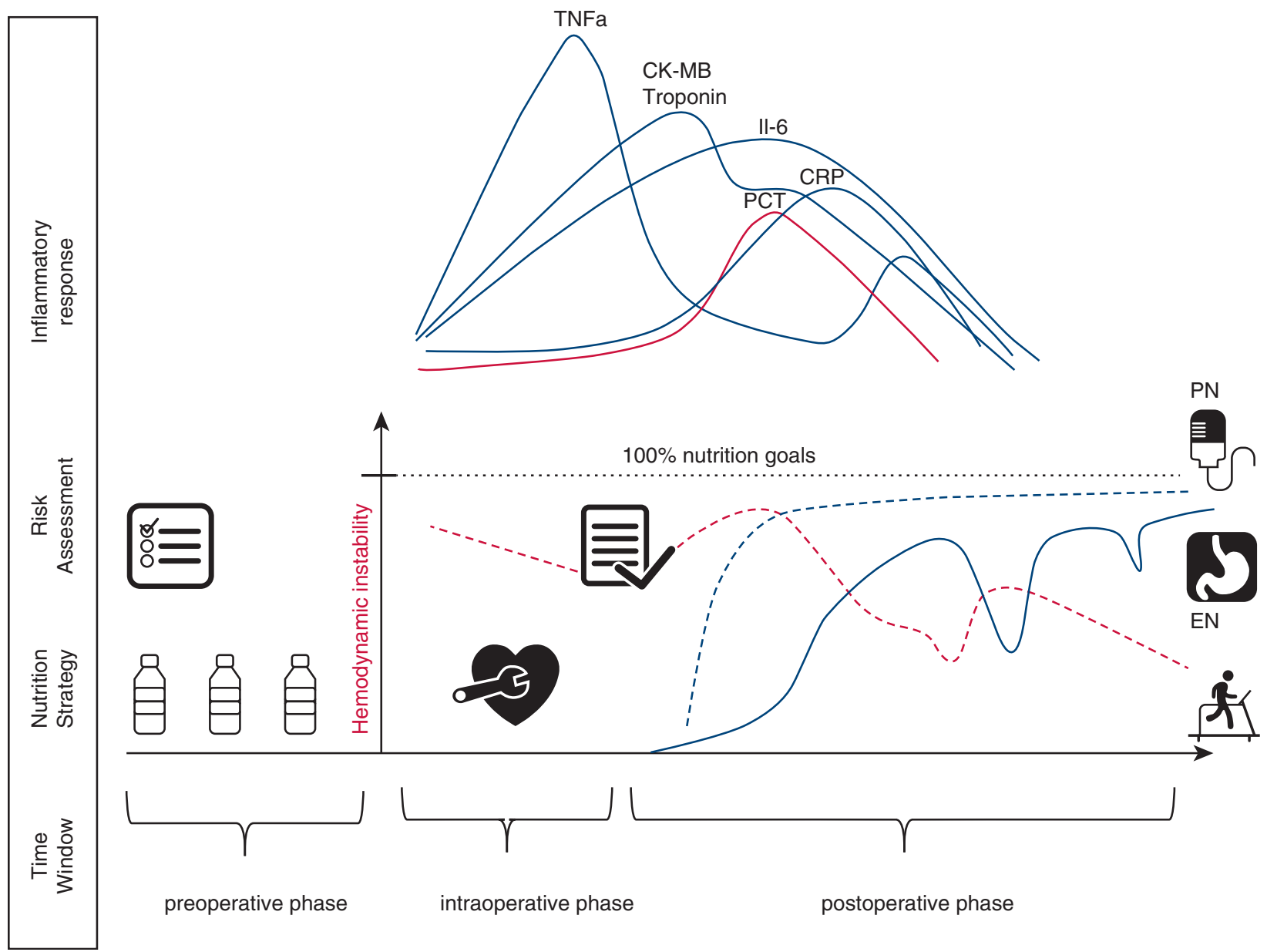

FIGURE 1. Perioperative nutrition support in high-risk cardiac surgery patients. A nutrition risk assessment should always be performed before initiation of nutrition support. Although a preoperative optimization could be achieved by oral intake (eg, oral nutrition supplements), a postoperative optimization may be achieved by a combined EN + PN feeding to decrease nutritional deficiencies. TNFa, Tumor necrosis factor alpha; $C K-M B$, creatine kinase-MB; $I L-6$, interleukin 6; $C R P$, C-reactive protein; $P C T$, procalcitonin; $P N$, parenteral nutrition; $E N$, enteral nutrition.

$\operatorname{study}^{43}$ ) is currently being formed to evaluate the clinical significance of a combined early postoperatively initiated ICU nutritional support and rehabilitation therapy in cardiac surgery patients to reduce prolonged ICU stay.

\section{MORE EVIDENCE IS NEEDED FOR PATIENTS REQUIRING EXTRACORPOREAL MEMBRANE OXYGENATION OR VENTRICULAR ASSIST DEVICE SUPPORT}

Although the use of extracorporeal life support (ECLS), including venovenous and venoarterial extracorporeal membrane oxygenation (ECMO) and ventricular assist devices (VADs), has grown rapidly over the past decade, there is little evidence on how and when to start feeding these critically ill patients. Currently, little data are available to what extent the degree of ventricular assistance (nonpulsatile or semi-pulsatile blood flow) may result in (long-term) gastrointestinal changes with respect to mesenteric blood flow, nutrient absorption, and bowel integrity. In patients with VADs, preliminary studies have demonstrated that gastrointestinal dysfunction, including satiety and nausea, slow the esophageal transit time and gastric emptying during the early postoperative course. ${ }^{44}$ Although recent guidelines state that EN is feasible during ECLS, these data are based on only 4 case series in adult patients with ECLS. ${ }^{45}$ In addition, several observational studies have reported nutritional support practices in patients with ECLS and demonstrated that EN was the most commonly used route of feeding, whereas underfeeding of either energy or protein occurred in approximately one-third of the nutrition support days. Medical procedures $(39.1 \%)$ and gastric motility disorders $(22.8 \%)$ were the most common reasons for interruption of nutritional support. ${ }^{45,46}$ Although coated circuits enabled a decrease in systemic anticoagulation, patients on ECMO and patients with VADs more often present with (gastrointestinal) bleeding or thrombotic 
complications, which likewise affect gastrointestinal integrity. Because gastrointestinal bleeding is one of the most common observed complications after VAD implantation, it may interfere with early EN strategies after device placement. ${ }^{47}$ Patients on ECMO and patients with VADs are more prone to develop gastrointestinal dysfunctions, EN feeding intolerance, and potential relative splanchnic hypoperfusion. Therefore, a combined $\mathrm{EN}+\mathrm{PN}$ strategy may help considering the advantages of EN by decreasing the overall functional intensity through reducing the EN rate, while covering the nutrition goals through additional PN.

Because patients with VADs and chronic heart failure show an increased risk of micronutrient deficiency, particularly vitamins $\mathrm{B}, \mathrm{C}$, and D and trace elements, ${ }^{45}$ the proposed combined EN + PN strategy may further represent an effective concept to compensate these deficiencies and to bridge the phase of acute critically illness until patients have stabilized.

\section{CONCLUSIONS}

Although nutritional support is straightforward, easily doable, proven safe, and clinically relevant, it remains largely inadequate in the treatment of cardiac surgery patients and those on ECLS. In the absence of specific guidelines, international initiatives are starting to establish specific protocols and strategies for these patients. Among these, high-dense EN and EN + PN may represent effective strategies to bridge the phase of acute critical illness and to reduce the nutritional deficiencies to provide a faster recovery of high-risk cardiac surgery patients with prolonged ICU stay. Several nutrition studies and innovative strategies are currently being tested to enhance recovery and improve outcomes after cardiac surgery.

\section{Conflict of Interest Statement}

R.C.A. received honoraria from Abbott Nutrition in the past. All other authors have nothing to disclose with regard to commercial support.

\section{References}

1. Sepehri A, Beggs T, Hassan A, Rigatto C, Shaw-Daigle C, Tangri N, et al. The impact of frailty on outcomes after cardiac surgery: a systematic review. J Thorac Cardiovasc Surg. 2014;148:3110-7.

2. Wischmeyer PE. Are we creating survivors... or victims in critical care? Delivering targeted nutrition to improve outcomes. Curr Opin Crit Care. 2016;22:279-84.

3. Arora RC, Manji RA, Singal RK, Hiebert B, Menkis AH. Outcomes of octogenarians discharged from the hospital after prolonged intensive care unit length of stay after cardiac surgery. J Thorac Cardiovasc Surg. 2017;154:1668-78.e2.

4. Manners JM. Nutrition after cardiac surgery. Anaesthesia. 1974;29:675-88.

5. Stoppe C, Goetzenich A, Whitman G, Ohkuma R, Brown T, Hatzakorzian R, et al. Role of nutrition support in adult cardiac surgery: a consensus statement from an international multidisciplinary expert group on nutrition in cardiac surgery. Crit Care. 2017;21:131.

6. Chermesh I, Hajos J, Mashiach T, Bozhko M, Shani L, Nir RR, et al. Malnutrition in cardiac surgery: food for thought. Eur J Prev Cardiol. 2014;21:475-83.
7. Sanchez JA, Sanchez LL, Dudrick SJ. Nutritional considerations in adult cardiothoracic surgical patients. Surg Clin North Am. 2011;91:857-75. ix.

8. Hill A, Nesterova E, Lomivorotov V, Efremov S, Goetzenich A, Benstoem C, et al. Current evidence about nutrition support in cardiac surgery patients-what do we know? Nutrients. 2018;10:597.

9. Chatterjee S, Shake JG, Arora RC, Engelman DT, Firstenberg MS, Geller CM, et al. Handoffs from the operating room to the intensive care unit after cardiothoracic surgery: from the Society of Thoracic Surgeons workforce on critical care. Ann Thorac Surg. 2019;107:619-30.

10. Kondrup J, Rasmussen HH, Hamberg O, Stanga Z, Ad Hoc ESPEN Working Group. Nutritional risk screening (NRS 2002): a new method based on an analysis of controlled clinical trials. Clin Nutr. 2003;22:321-36.

11. Wei X, Day AG, Ouellette-Kuntz H, Heyland DK. The association between nutritional adequacy and long-term outcomes in critically ill patients requiring prolonged mechanical ventilation: a multicenter cohort study. Crit Care Med. 2015;43:1569-79.

12. Faisy C, Lerolle N, Dachraoui F, Savard JF, Abboud I, Tadie JM, et al. Impact of energy deficit calculated by a predictive method on outcome in medical patients requiring prolonged acute mechanical ventilation. Br J Nutr. 2009;101:1079-87.

13. Stoppe C, Ney J, Lomivorotov VV, Efremov SM, Benstoem C, Hill A, et al. Prediction of prolonged ICU stay in cardiac surgery patients as a useful method to identify nutrition risk in cardiac surgery patients: a post hoc analysis of a prospective observational study. JPEN J Parenter Enteral Nutr. 2018;18:971.

14. Stoppe C, McDonald B, Rex S, Manzanares W, Whitlock R, Fremes S, et al. SodiUm SeleniTe Adminstration IN Cardiac Surgery (SUSTAIN CSX-trial): study design of an international multicenter randomized double- blinded controlled trial of high dose sodium-selenite administration in high-risk cardiac surgical patients. Trials. 2014;15:339.

15. Singer P, Blaser AR, Berger MM, Alhazzani W, Calder PC, Casaer MP, et al. ESPEN guideline on clinical nutrition in the intensive care unit. Clin Nutr. 2019;38: 48-79.

16. Rahman A, Hasan RM, Agarwala R, Martin C, Day AG, Heyland DK. Identifying critically-ill patients who will benefit most from nutritional therapy: further validation of the "modified NUTRIC" nutritional risk assessment tool. Clin Nutr. 2016;35:158-62.

17. Venkateswaran RV, Charman SC, Goddard M, Large SR. Lethal mesenteric ischaemia after cardiopulmonary bypass: a common complication? Eur J Cardiothorac Surg. 2002;22:534-8.

18. Heyland DK, Dhaliwal R, Wang M, Day AG. The prevalence of iatrogenic underfeeding in the nutritionally "at-risk" critically ill patient: results of an international, multicenter, prospective study. Clin Nutr. 2015;34:659-66.

19. TARGET Investigators, for the ANZICS Clinical Trials Group, Chapman M Peake SL, Bellomo R, Davies A, Deane A, et al. Energy-dense versus routine enteral nutrition in the critically ill. N Engl J Med. 2018;379:1823-34.

20. Hoffer LJ, Bistrian BR. Appropriate protein provision in critical illness: a systematic and narrative review. Am J Clin Nutr. 2012;96:591-600.

21. National Heart, Lung, and Blood Institute Acute Respiratory Distress Syndrome (ARDS) Clinical Trials Network, Rice TW, Wheeler AP, Thompson BT, Steingrub J, Hite RD, et al. Initial trophic vs full enteral feeding in patients with acute lung injury: the EDEN randomized trial. JAMA. 2012;307:795-803.

22. Arabi YM, Aldawood AS, Haddad SH, Al-Dorzi HM, Tamim HM, Jones G, et al. Permissive underfeeding or standard enteral feeding in critically ill adults. $N$ Engl J Med. 2015;372:2398-408.

23. Heidegger CP, Berger MM, Graf S, Zingg W, Darmon P, Costanza MC, et al. Optimisation of energy provision with supplemental parenteral nutrition in critically ill patients: a randomised controlled clinical trial. Lancet. 2013;381:385-93.

24. Singer P, Anbar R, Cohen J, Shapiro H, Shalita-Chesner M, Lev S, et al. The tight calorie control study (TICACOS): a prospective, randomized, controlled pilot study of nutritional support in critically ill patients. Intensive Care Med. 2011; 37:601-9.

25. Heyland DK, Dhaliwal R, Jiang X, Day AG. Identifying critically ill patients who benefit the most from nutrition therapy: the development and initial validation of a novel risk assessment tool. Crit Care. 2011;15:R268.

26. Marik PE, Zaloga GP. Early enteral nutrition in acutely ill patients: a systematic review. Crit Care Med. 2001;29:2264-70.

27. Doig GS, Heighes PT, Simpson F, Sweetman EA, Davies AR. Early enteral nutrition, provided within $24 \mathrm{~h}$ of injury or intensive care unit admission, significantly reduces mortality in critically ill patients: a meta-analysis of randomised controlled trials. Intensive Care Med. 2009;35:2018-27.

28. Reignier J, Boisramé-Helms J, Brisard L, Lascarrou JB, Ait Hssain A, Anguel N, et al. Enteral versus parenteral early nutrition in ventilated adults with shock: a 
randomised, controlled, multicentre, open-label, parallel-group study (NUTRIREA-2). Lancet. 2018;391:133-43.

29. Mazaki T, Ebisawa K. Enteral versus parenteral nutrition after gastrointestinal surgery: a systematic review and meta-analysis of randomized controlled trials in the English literature. J Gastrointest Surg. 2008;12:739-55.

30. Drover JW, Cahill NE, Kutsogiannis J, Pagliarello G, Wischmeyer P, Wang M, et al. Nutrition therapy for the critically ill surgical patient: we need to do better! JPEN J Parenter Enteral Nutr. 2010;34:644-52.

31. Fan M, Wang Q, Fang W, Jiang Y, Li L, Sun P, et al. Early enteral combined with parenteral nutrition treatment for severe traumatic brain injury: effects on immune function, nutritional status and outcomes. Chin Med Sci J. 2016;31:213-20.

32. Wischmeyer PE, Hasselmann M, Kummerlen C, Kozar R, Kutsogiannis DJ, Karvellas CJ, et al. A randomized trial of supplemental parenteral nutrition in underweight and overweight critically ill patients: the TOP-UP pilot trial. Crit Care. 2017;21:142

33. Dellinger RP, Levy MM, Rhodes A, Annane D, Gerlach H, Opal SM, et al. Surviving sepsis campaign: international guidelines for management of severe sepsis and septic shock: 2012. Crit Care Med. 2013;41:580-637.

34. Dhaliwal R, Cahill N, Lemieux M, Heyland DK. The Canadian critical care nutrition guidelines in 2013: an update on current recommendations and implementation strategies. Nutr Clin Pract. 2014;29:29-43.

35. McClave SA, Taylor BE, Martindale RG, Warren MM, Johnson DR, Braunschweig C, et al. Guidelines for the provision and assessment of nutrition support therapy in the adult critically ill patient: Society of Critical Care Medicine (SCCM) and American Society for Parenteral and Enteral Nutrition (A.S.P.E.N.). JPEN J Parenter Enteral Nutr. 2016;40:159-211.

36. Casaer MP, Mesotten D, Hermans G, Wouters PJ, Schetz M, Meyfroidt G, et al. Early versus late parenteral nutrition in critically ill adults. N Engl J Med. 2011;365:506-17.

37. Kelly DG, Tappenden KA, Winkler MF. Short bowel syndrome: highlights of patient management, quality of life, and survival. JPEN J Parenter Enteral Nutr. 2014;38:427-37.
38. Harvey SE, Parrott F, Harrison DA, Bear DE, Segaran E, Beale R, et al. Trial of the route of early nutritional support in critically ill adults. N Engl J Med. 2014; 371:1673-84.

39. Kress JP, Hall JB. ICU-acquired weakness and recovery from critical illness. $N$ Engl J Med. 2014;371:287-8.

40. Fan E, Cheek F, Chlan L, Gosselink R, Hart N, Herridge MS, et al. An official American Thoracic Society clinical practice guideline: the diagnosis of intensive care unit-acquired weakness in adults. Am J Respir Crit Care Med. 2014;190: 1437-46.

41. Heyland DK, Stapleton RD, Mourtzakis M, Hough CL, Morris P, Deutz NE, et al. Combining nutrition and exercise to optimize survival and recovery from critical illness: conceptual and methodological issues. Clin Nutr. 2016:35:1196-206.

42. Hermans G, Van Mechelen H, Clerckx B, Vanhullebusch T, Mesotten D Wilmer A, et al. Acute outcomes and 1-year mortality of intensive care unit acquired weakness. A cohort study and propensity-matched analysis. Am J Re spir Crit Care Med. 2014;190:410-20.

43. Uniklinik RWTH Aachen. Available at: https://www.ukaachen.de/en/clinics institutes/3care/research.html. Accessed June 3, 2019.

44. el-Amir NG, Gardocki M, Levin HR, Markowitz DD, Greenspan RL, Catanese KA, et al. Gastrointestinal consequences of left ventricular assist device placement. ASAIO J. 1996;42:150-3.

45. Stoppe C, Nesterova E, Elke G. Nutritional support in patients with extracorporeal life support and ventricular assist devices. Curr Opin Crit Care. 2018;24 269-76.

46. Ferrie S, Herkes R, Forrest P. Nutrition support during extracorporeal membrane oxygenation (ECMO) in adults: a retrospective audit of 86 patients. Intensive Care Med. 2013:39:1989-94.

47. Morgan JA, Paone G, Nemeh HW, Henry SE, Patel R, Vavra J, et al. Gastrointestinal bleeding with the HeartMate II left ventricular assist device. J Heart Lung Transplant. 2012;31:715-8. 